\title{
"An Experimental Study to Prediction the Life Span of Unbacked Flexible PVC Flooring With Respected to Aging, Thermal Behaviour and Physical Properties"
}

\author{
Anant pandey ${ }^{\mathrm{a}}$, Prabhash Jain ${ }^{\mathrm{b}}$ \\ ${ }^{a}$ M.tech, BUIT, Bhopal \\ ${ }^{b} \mathrm{HOD}$, Department of mechanical engineering, BUIT, Bhopal
}

\begin{abstract}
There are lot of plastic materials (PVC) being used in various applications and sometimes it requires knowing the life time of the products used in some critical application. These predictions of service life enable to understand and benchmark product life cycles in the application field.

In the present project work we have studied the Thickness, Tensile Strength, Ply adhesion, Dimensional stability of PVC as a function of time with the constant exposure to the plastic product at $70^{\circ} \mathrm{C}$ for 24 week. The above mentioned properties were studied periodically as zero day sample or base property of the material. The regression analysis was conducted on the above test data and the prediction of the life span of the products was made as per ASTM.
\end{abstract}

Key Words: PVC, Flexible PVC Flooring, Dimension Stability, Tensile Strength, Ply Adhesion.

\section{Introduction}

Poly vinyl chloride (PVC) products are predominantly employed in long-life construction applications. As one of the most relevant polymers for construction and commodities, PVC is a thoroughly investigated material. Initially the production was subject to scrutiny, but later attention broadened to encompass the whole product life cycle. The guiding principle of sustainability presents specific challenges to polymers in general and to PVC compounds in particular. These challenges relate to carbon neutrality, chlorinated compounds, and the use of additives. Among the various additives of PVC products, plasticisers and stabilisers are particularly important. Plasticisers, primarily phthalates, are added to the originally rigid PVC polymer in order to make flexible products. Stabilisers are indispensable to provide the necessary stability of the PVC polymer against heat, light and weathering. Applicable stabilisers are heavy metal and organising compounds as well as organic co-stabilisers, depending on the desired product properties [1].

Poly vinyl chloride (PVC) is the world's most versatile thermoplastics with a wide range of applications than any other plastics. It plays an important role in every field such as agriculture, electrical, irrigation, house roofs, shoe soles and many other fields. It is having limited thermal stability. Polyvinyl chloride (PVC) is a popular thermoplastic that contains high levels of chlorine which can reach up to $57 \%$. Carbon, which is derived from oil or gas, is also used in its fabrication. It is an odourless and solid plastic that is white, brittle and can also be found on the market in the form of pellets or white powder. PVC resin is often supplied in the powder forms and its high resistance to oxidation and degradation make it possible to store the material for long periods. Some authors/activists that oppose the manufactures of PVC often refer to it as the "Poison Plastic" due to the toxic pollutants it might release. When plasticizers are added it becomes softer and more flexible [2].

Concepts of poly vinyl chloride production:-

Commercial Method

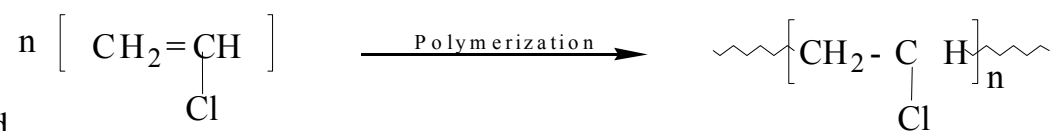

Vinyl chloride monomer is prepared by cracking 1, 2-dichloro ethane.

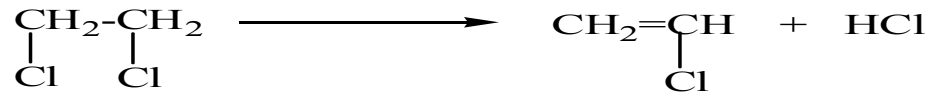

- Vinyl Chloride may be produced by the addition of $\mathrm{HCl}$ to acetylene.

$$
\mathrm{HC} \equiv \mathrm{CH}+\mathrm{HCl} \longrightarrow \mathrm{CH}_{2}=\mathrm{CH}+95.5 \mathrm{KJ} / \mathrm{mol}
$$

The flexible PVC flooring shall consist of a thoroughlyblended Composition of thermoplastic binder; fillers and pigments. There are two kinds of PVC flooring. One is flexible, which is available in sheet form and 
the other rigid which is available in standard tile sizes. Flexible PVC flooring is suitable for comparatively lighter traffic, either for rigid floors such as concrete and stone flooring or for flexible floors such as timber flooring, etc. Flexible PVC flooring has been in use in the country for more than a decade. It provides dust free, noise absorbing resilient and decorative surface for building of various types. The floor covering is available in different shades and designs [3].

\section{Experimental Procedure:}

The failure criterion may be defined as an unacceptable change in the function which causes a particular failure. Changes may be in physical properties, ply adhesion, stress relaxation, stiffness/modulus, creep, tear resistance, swelling, dielectric properties, etc.

The underlying mechanism involved in this change must be determined by an accelerated laboratory test at different levels of severity and at different time intervals. It is important to keep the accelerated test condition similar to the service condition and perform the test at multiple temperatures.

Stage-I:-Preparation of specimens is according to the time and temperature to be exposed.

1. For dimension stability, the test specimen shall be a strip of flooring $1.52 \mathrm{~mm}$ thickness, $200 \mathrm{~mm}$ width, $200 \mathrm{~mm}$ Length. Five specimen cut from widely separated parts of the flooring sheet.

2. For Tensile strength, the test specimen shall be a strip of flooring $25 \mathrm{~mm}$ width, $150 \mathrm{~mm}$ Length. Five specimen cut from widely separated parts of the flooring sheet.

3. For Ply Adhesion, The test specimen shall be a strip of the flooring $50 \mathrm{~mm}$ wide and $225 \mathrm{~mm}$ long. Five specimens cut from widely separated parts of the flooring sheet.

Stage-II: - Exposure of samples at different temperature in oven.

1. The flooring shall be taken and shall be maintained at a temperature of $70 \pm 1^{\circ} \mathrm{C}$ in oven. The samples are placed in an aging oven. The temperature and the duration are specified by the customer. The specimens are removed and tested after oven aging is complete.

Stage-III:-Properties evaluation at different temperature levels in UTM Machine.

\section{Properties Evaluation in:}

1. Tensile strength

2. Ply adhesion

3. Dimension stability

Stage-IV:- Regression analysis of the plastic products which is tested.

Regression models involve the following variables:

- The unknown parameters, denoted as $b$, which may represent a scalar or a vector.

- The independent variables $X_{i}$ in this case $X_{i}$ is time period in week).

- The dependent variable, $Y_{i}$ (in this case $Y_{i}$ is properties value for particular time period).

In various fields of application, different terminologies are used in place of dependent and independent variables.

In linear regression, the model specification is that the dependent variable, $\mathrm{Y}$ is a linear combination of the parameters (in this case life prediction of product).

For example, in simple linear regression for modelling $\mathbf{n}$ data points there is one independent variable: $\mathbf{x}_{\mathbf{i}}$, and two parameters, $\mathbf{b}_{\mathbf{0}}$ and $\mathbf{b}_{\mathbf{1}}$ :

Straight line: $\quad \mathrm{Y}=\mathrm{b}_{0}+\mathrm{b}_{1} \mathrm{x}_{0}$

The residual, $\mathrm{Y}_{\mathrm{i}-\mathrm{y}} \mathrm{y}$, is the difference between the value of the dependent variable predicted by the model, $y$, and the true value of the dependent variable, $Y_{\mathrm{i}}$. One method of estimation is ordinary least squares. This method obtains parameter estimates that minimize the sum of squared residuals, SSE, also sometimes denoted RSS:

$$
\operatorname{SSE}=\sum_{\mathrm{i}=1}^{\mathrm{n}}\left(\mathrm{Y}_{\mathrm{i}}-\mathrm{y}\right)^{2}
$$

Minimization of this function results in a set of normal equations, a set of simultaneous linear equations in the parameters, which are solved to yield the parameter estimators, $b_{0}, b_{1}$.

$$
\begin{gathered}
\mathrm{b}_{0}=\mathrm{y}+\mathrm{b}_{1} \mathrm{x} \\
\left.\mathrm{b}_{1}=\sum(\mathrm{x}-\mathrm{Xi})(\mathrm{y}-\mathrm{Yi})\right) / \sum(\mathrm{Xi}-\mathrm{x})^{2}
\end{gathered}
$$

Put the value $b_{0}, b_{1}$ in above equation and find out the value of $Y$. The value of $Y$ gives the life of prediction of unbacked flexible PVC Flooring [17]. 


\section{Result And Discussion:}

In the present investigation the Thickness, Tensile Strength, Ply adhesion, Dimensional stability, was determined as a function of time with the constant exposure to the plastic product at $70^{\circ} \mathrm{C}$ for 24 week. The sample was initially determined the above properties and considered as 0 days sample or base property of the material. The sample was drawn in the interval of B-3, 8, 13, 18, 24 Weeks.

The regression analysis was conducted on the above test data and the prediction of the life span of the products was made as per ASTM. Use the regression equation to determine the exposure time necessary to produce a predetermined level of property change. An acceptable regression equation must have at least $80 \%$.

Table 1. Periodically Flexible Pve Flooring Dimension AT $70^{\circ} \mathrm{C}$ :

\begin{tabular}{|c|c|c|c|c|}
\hline S. No. & Week & Thickness & Width & Length \\
\hline 1. & 0 & 1.52 & 200 & 200 \\
\hline 2. & 3 & 1.52 & 199.99 & 200 \\
\hline 3. & 8 & 1.51 & 200 & 200 \\
\hline 4. & 13 & 1.52 & 200 & 200 \\
\hline 5. & 18 & 1.52 & 200 & 200 \\
\hline 6. & 24 & 1.51 & 200 & 200 \\
\hline
\end{tabular}

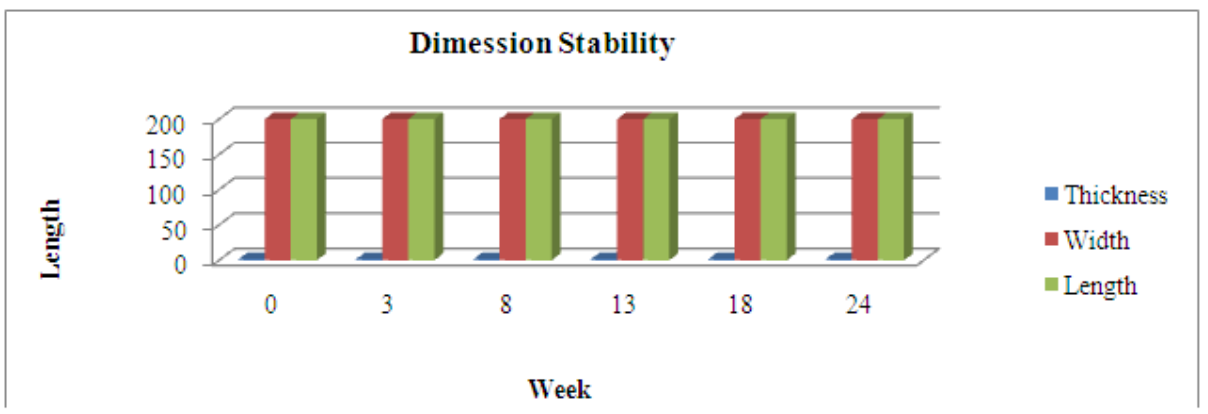

Fig.1. Dimension stability

Table 2. Periodically Flexible Pvc Flooring Tensile Strength At $\quad \mathbf{7 0}^{\circ} \mathrm{C}$ :

\begin{tabular}{|c|c|}
\hline Week & Tensile strength(N/. $\left.\mathbf{m m}^{\mathbf{2}}\right)$ \\
\hline 0 & 9.85 \\
\hline 3 & 9.84 \\
\hline 8 & 9.71 \\
\hline 13 & 9.42 \\
\hline 24 & 9.36 \\
\hline
\end{tabular}

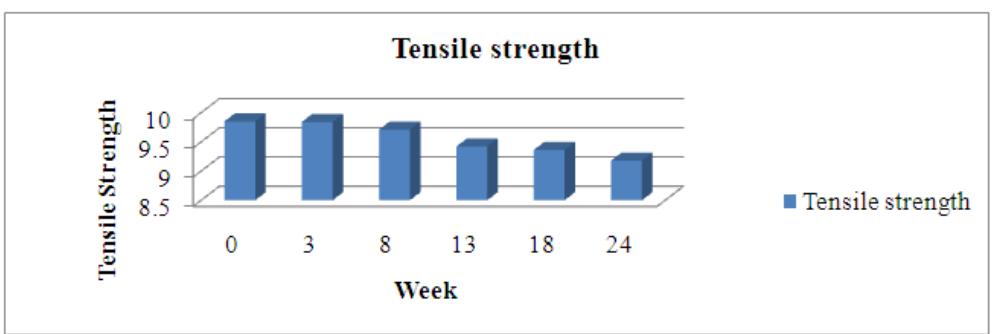

Fig. 2. Tensile Strength

Table No. 3. Periodically Flexible Pve Flooring Ply Adhesion At $70^{\circ} \mathrm{C}$ :

\begin{tabular}{|c|c|}
\hline Week & PLY ADHESION (KN/m) \\
\hline 0 & 1.61 \\
\hline 3 & 1.6 \\
\hline 8 & 1.58 \\
\hline 13 & 1.54 \\
\hline 18 & 1.49 \\
\hline 24 & 1.45 \\
\hline
\end{tabular}




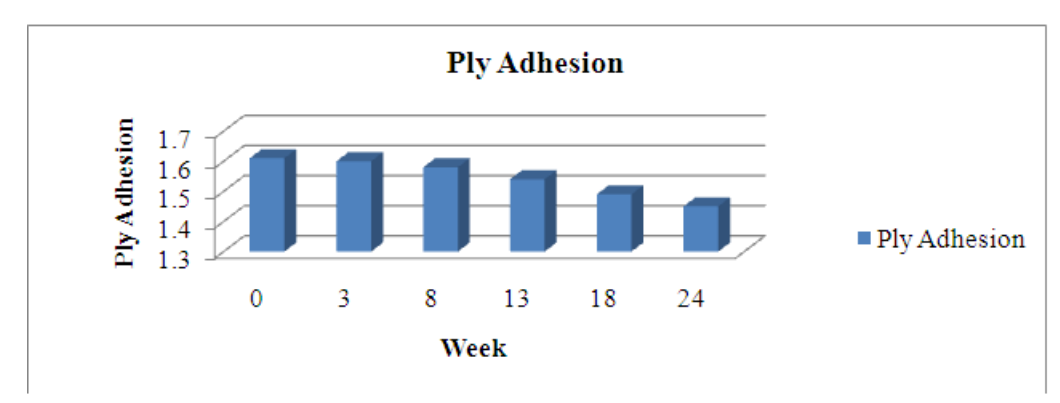

Table No. 4.4. (b) Ply Adhesion

Table No. 4.5 (a) Regression Analysis Of Tensile Strength $\left(\mathrm{N} / \mathrm{mm}^{2}\right)$

Prediction of time period for $80 \%$ deterioration Tensile Strength to the Average Tensile strength values calculated for 24 weeks

\begin{tabular}{|c|c|c|c|c|c|c|c|}
\hline Sl No & $\mathrm{Xi}$ & Yi & $\mathrm{Xi}-\mathrm{x}$ & Yi-y & $(\mathrm{Xi}-\mathrm{x})^{2}$ & $(Y i-y)^{2}$ & $(x-X i)(y-Y i)$ \\
\hline 1 & 0 & 9.85 & -11 & 0.29 & 121 & 0.0841 & -3.19 \\
\hline 2 & 3 & 9.84 & -8 & 0.28 & 64 & 0.0784 & -2.24 \\
\hline 3 & 8 & 9.71 & -3 & 0.15 & 9 & 0.0225 & -0.45 \\
\hline 4 & 13 & 9.42 & 2 & -0.14 & 4 & 0.0196 & -0.28 \\
\hline 5 & 18 & 9.36 & 7 & -0.2 & 49 & 0.04 & -0.14 \\
\hline 6 & 24 & 9.18 & 13 & -0.38 & 169 & 0.1444 & -4.94 \\
\hline sum & 66 & 57.36 & $\mathbf{0}$ & $\mathbf{0}$ & 416 & 0.389 & -11.25 \\
\hline Avg & $x=11$ & $y=9.56$ & & & & & \\
\hline $\mathrm{Y}=$ & \multicolumn{7}{|c|}{$\mathrm{b}_{0}+\mathrm{b}_{1} \mathrm{x}$} \\
\hline$b_{1}=$ & \multicolumn{7}{|c|}{$\left.\sum(\mathrm{x}-\mathrm{Xi})(\mathrm{y}-\mathrm{Yi})\right) / \sum(\mathrm{Xi}-\mathrm{x})^{2}$} \\
\hline $\mathrm{b}_{0}$ & \multicolumn{7}{|c|}{$\mathrm{y}+\mathrm{b}_{1} \mathrm{x}$} \\
\hline$b_{1}$ & \multirow{2}{*}{\multicolumn{7}{|c|}{$\begin{array}{c}-0.027043 \\
11.297476\end{array}$}} \\
\hline $\mathrm{b}_{0}$ & & & & & & & \\
\hline $\mathbf{Y}$ & \multicolumn{7}{|c|}{$11.297476-0.027043 x$} \\
\hline \multicolumn{8}{|c|}{ Where } \\
\hline \multirow{2}{*}{\multicolumn{8}{|c|}{$\begin{array}{c}\mathrm{X}_{\mathrm{i}} \text {-Time period (in weeks) } \\
\text { Yi- Tensile strength values for particular time period }\end{array}$}} \\
\hline & & \multicolumn{5}{|c|}{ Yi- Tensile strength values for particular time period } & \\
\hline
\end{tabular}

Table No. 4.5 (b) Regression Analysis Of Ply Adhesion (KN/m)

Prediction of time period for $80 \%$ deterioration Ply Adhesion to the Average Ply Adhesion values calculated for 24 weeks

\begin{tabular}{|c|c|c|c|c|c|c|c|}
\hline S. No. & $\mathrm{Xi}$ & Yi & $\mathrm{Xi-X}$ & Yi-y & $(\mathrm{Xi}-\mathrm{x})^{2}$ & $(Y i-y)^{2}$ & $(x-X i)(y-Y i)$ \\
\hline 1 & 0 & 1.61 & -11 & 0.065 & 121 & 0.004225 & -0.715 \\
\hline 2 & 3 & 1.6 & -8 & 0.055 & 64 & 0.003025 & -0.44 \\
\hline 3 & 8 & 1.58 & -3 & 0.035 & 9 & 0.001225 & -0.105 \\
\hline 4 & 13 & 1.54 & 2 & -0.005 & 4 & 0.000025 & -0.01 \\
\hline 5 & 18 & 1.49 & 7 & -0.055 & 49 & 0.003025 & -0.385 \\
\hline 6 & 24 & 1.45 & 13 & -0.095 & 169 & 0.009025 & -1.235 \\
\hline Sum & 66 & 9.27 & $\mathbf{0}$ & $\mathbf{0}$ & 416 & 0.02055 & -2.89 \\
\hline Avg & $x=11$ & $\mathrm{y}=1.545$ & & & & & \\
\hline $\mathrm{Y}$ & \multicolumn{7}{|c|}{$\mathrm{b}_{0}+\mathrm{b}_{1} \mathrm{x}$} \\
\hline$b_{1}$ & \multicolumn{7}{|c|}{$\left.\sum(\mathrm{x}-\mathrm{Xi})(\mathrm{y}-\mathrm{Yi})\right) / \sum(\mathrm{Xi}-\mathrm{x})^{2}$} \\
\hline $\mathrm{b}_{0}$ & \multirow{2}{*}{\multicolumn{7}{|c|}{$\mathrm{y}+\mathrm{b}_{1} \mathrm{x}$}} \\
\hline $\mathrm{b}_{1}$ & \multirow{2}{*}{\multicolumn{7}{|c|}{$\begin{array}{c}-0.0069471 \\
1.4685817\end{array}$}} \\
\hline $\mathrm{b}_{0}$ & & & & & & & \\
\hline $\mathbf{Y}$ & \multicolumn{7}{|c|}{$1.4685817-0.0069471 x$} \\
\hline \multicolumn{8}{|c|}{ Where } \\
\hline \multicolumn{8}{|c|}{$\mathrm{X}_{\mathrm{i}}$-Time period (in weeks) } \\
\hline & & & ly $\mathrm{Ad}$ & alues for & r time $p$ & & \\
\hline
\end{tabular}

Hence by above equation, the decrease of $80 \%$ of Avg. Ply Adhesion values Predicted for $0-24$ week is 1.5 year's appx. 


\section{Conclusion:}

The above studies have been done based on the ASTM D 3045 and regression analysis was conducted on the properties obtained in the interval of time duration of B-0,3,8,13,18,24 Weeks. The analysis was shown the below prediction of the life time of the product:

\begin{tabular}{|c|c|c|}
\hline So. No. & Properties & $\begin{array}{c}\text { Life Span Of Calculated Regression } \\
\text { Analysis } \\
\text { (Years) }\end{array}$ \\
\hline 1. & Dimension Stability & $99.9 \%$ \\
\hline 2. & Tensile Strength & $11 \%$ \\
\hline 3. & Ply Adhesion & $1.5 \%$ \\
\hline
\end{tabular}

The above properties are not directly affect the product life with respect to the time and hence can be omitted to predict the life time of the product.

Based on the above regression analysis and data interpretation generated after exposure to the product for the $70^{\circ}$ C B - 0,3,8,13,18,24 Weeks it was concluded that the Dimensions Stability, Tensile Strength, Ply Adhesions can be considered for the prediction of life time of The product.

\section{References:}

[1]. Ivo Mersiowsky TUHH Technologies GmbH (TuTech), Integrated Management, Schellerdamm 4, D-21079 Hamburg, Germany, Polymer. Sci. 27 (2002) 2227-2277.

[2]. http://composite.about.com/od/Plastics/a/What-Is-Pvc-Plastics.htm.

[3]. https://law.resource.org/pub/in/bis/S03/is.3462.1986.

[4]. Garcia D, Balart R, Crespo JE, Lopez J. Mechanical properties of recycled PVC blends with styrenic polymers. J Appl Polymer Sci 2006; 101:2464e71.

[5]. Kaufman M. The history of PVC, the chemistry and industrial production of polyvinyl chloride. London: McLaren and Sons Ltd., 1969.

[6]. Furukawa Y. Staudinger, Carothers, and the emergence of macromolecular chemistry. Ph.D. dissertation, University of Oklahoma, 1983.

[7]. Plastics Additives \& Compounding September/October 2004, ISSN1464-391X/04 2004 Elsevier Ltd.

[8]. Kaufman M. The history of PVC, the chemistry and industrial production of polyvinyl chloride. London: Maclaren and Sons Ltd., 1969.

[9]. Krekeler K, Wick G. Poly vinyl chloride. Herstellung, Eigenschaften, Verarbeitung und Annwendung. In: Kunststoff-Handbuch Volume 2: Polyvinylchloride. Munich: Carl Hanser Verlag, 1963.

[10]. Coleman DC. Courtaulds, an Economic and Social History II: Rayon. Oxford: Clarendon Press, 1969.

[11]. Beer EJ. The beginning of rayon. Paignton (Devon, UK): Beer, 1962.

[12]. Reverdin F. U” ber die Chemists Industries der Schweiz im Jahre 1899. Die Chemische Industries 1900; 23(22):483.

[13]. Pistor G. Hundert Jahre Griesheim 1856-1956 Ein Beitrag zur Geschichte der chemischen Industries. Tegernsee/Obb., 1958.

[14]. Semon WL, Stahl GH. History of vinyl chloride polymers. In: Seymour RB, editor. History of polymer science and technology. New York and Basel: Marcel Dekker Inc., 1982:199-214.

[15]. www.atofina.com, Atlas Material Testing Technology.

[16]. www.cibasc.com/plastics, Crompton Corporation.

[17]. www.wikipedia.com. 